\title{
Neuroendocrine Tumor of the Hilar Bile Duct
}

\author{
NAOKI UMEZAKI, DAISUKE HASHIMOTO, YO-ICHI YAMASHITA, SHIGEKI NAKAGAWA, \\ YOUSUKE NAKAO, RUMI ITOYAMA, TOSHIHIKO YUSA, TAKANOBU YAMAO, HIROHISA OKABE, \\ KATSUNORI IMAI, HIROMITSU HAYASHI, AKIRA CHIKAMOTO and HIDEO BABA \\ Department of Gastroenterological Surgery, \\ Kumamoto University Graduate School of Medical Sciences, Kumamoto, Japan
}

\begin{abstract}
Neuroendocrine tumors usually develop in the gastrointestinal tract, pancreas, and lung. Therefore, a neuroendocrine tumor of the bile duct is quite rare. We present a 59-year-old-male patient whose preoperative diagnosis was hilar cholangiocarcinoma. One month after embolization of the left branch and anterior branch of the portal vein, he underwent left hepatic trisegmentectomy and extrahepatic bile duct resection. Pathological examination revealed the neuroendocrine tumor in the submucosal layer of the hilar bile duct. Because there was no neuroendocrine tumor in other organs, the tumor was considered a primary neuroendocrine tumor of the hilar bile duct, rather than a liver metastasis from other organs. We also present a review of the English literature regarding neuroendocrine tumors of the bile duct.
\end{abstract}

Neoplasms of the extrahepatic bile duct are uncommon gastrointestinal tumors (1-3). The most common neoplasm arising from the biliary tree is adenocarcinoma, accounting for up to $80 \%$ of all bile duct tumors $(1,3-5)$.

Neuroendocrine tumors (NET) are considered relatively rare tumors (4). NET are usually developed in the gastrointestinal tract, pancreas, and lung $(4,5)$. NET of the extrahepatic bile duct is exceedingly rare, and accounts for $0.1 \%$ to $0.2 \%$ of NETs of the gastrointestinal tract (3).

As there was a small number of similar cases in the English literature, we would like to present a case of NET of the hilar bile duct. We also present a review of the English literature regarding similar cases to summarize the diagnosis and treatment of patients with this tumor, which is difficult to diagnose pre-operatively and distinguish from cholangiocarcinoma.

Correspondence to: Hideo Baba, MD, Ph.D., F.A.C.S., Department of Gastroenterological Surgery, Kumamoto University Graduate School of Medical Sciences, 1-1-1 Honjo, Chuo-ku, Kumamoto 860-8556, Japan. Tel: +81 963735213, Fax: +81 963714378, e-mail: hdobaba@kumamoto-u.ac.jp

Key Words: Neuroendocrine tumor, bile duct tumor, operation.

\section{Case Report}

A 59-year-old-man was referred to us because of elevated $\gamma$-GTP $(265 \mathrm{U} / \mathrm{l})$ and the ultrasonographic dilatation of intrahepatic bile ducts (IHBD), which were pointed out in the annual comprehensive medical checkup.

In further examination, a contrast-enhanced computed tomography (CT) scan revealed a $27 \mathrm{~mm}$ tumor with ring enhancement at the hepatic portal region (Figure 1A), and dilatation of IHBD. Magnetic resonance cholangiopancreatography indicated a defect in the visualized bile duct consistent with the tumor and dilatation of the intrahepatic bile duct (Figure 1B). The patient was preoperatively diagnosed with a hilar cholangiocarcinoma. Because he did not show jaundice and his total bilirubin was not elevated $(1.1 \mathrm{mg} / \mathrm{dl})$, endoscopic retrograde cholangiopancreatography (ERCP) was not planned. No evidence of distant metastasis was identified. Tumor markers were not elevated (carcinoembryonic antigen $1.7 \mathrm{mg} / \mathrm{ml}$, carbohydrate antigen 19-9 $0.6 \mathrm{U} / \mathrm{ml}$ ).

Because the tumor involved the left hepatic duct and the branch of the bile duct of the anterior segment, we planned a left hepatic trisegmentectomy and extrahepatic bile duct resection. CT-volumetry revealed that the expected volume of the posterior segment was $38.8 \%$ (Figure 2A and B). To reduce the loss of liver function by the hepatic resection, embolization of the left branch and anterior branch of the portal vein was performed before surgery. One month after, the expected volume of the posterior segment was increased to $51.2 \%$. Finally, the operation was performed as planned. Intraoperative frozen pathology showed no malignant tumor at the proximal cut end of the common bile duct, and at the distal cut end of the posterior branch. Hepaticojejunostomy with Roux-en-Y reconstruction was performed.

Macroscopically, the tumor appeared as a submucosal tan nodule measuring $2.5 \times 2.0 \mathrm{~cm}$, arising at the common hepatic duct bifurcation and extending into the left hepatic duct (Figure $3 \mathrm{~A}$ and $\mathrm{B}$ ). The tumor extended through the bile wall. Microscopically, the tumor was composed of sheets of uniform cells with granular cytoplasm and central and round nuclei with coarse and clustered chromatin (Figure 4A). 
Table I. Literature review of NET generated from common hepatic duct published from 1986 to 2017, excluding our case.

\begin{tabular}{|c|c|c|}
\hline \multicolumn{2}{|l|}{ Number of patients (n) } & 25 \\
\hline Male: Female $(\mathrm{n}, \%)$ & & $8(32.0): 17(68.0)$ \\
\hline Median age (y.o., range) & & $37(6-71)$ \\
\hline \multirow[t]{5}{*}{ Symptoms $(\mathrm{n}, \%)$} & Jaundice & $15(60.0)$ \\
\hline & Abdominal pain & $9(36.0)$ \\
\hline & Weight loss & $4(16.0)$ \\
\hline & Nausea/vomiting & $3(12.0)$ \\
\hline & Cholangitis/fever & $2(8.0)$ \\
\hline Median tumor size (mm, range) & & $27(6-55)$ \\
\hline \multirow[t]{4}{*}{ Tumor location $(\mathrm{n}, \%)$} & Common hepatic duct & $13(52.0)$ \\
\hline & Common hepatic duct bifurcation & $8(32.0)$ \\
\hline & Cystic Duct-Common hepatic duct & $3(12.0)$ \\
\hline & Right hepatic duct-Common hepatic duct & $1(4.0)$ \\
\hline \multirow[t]{3}{*}{ Metastasis (n, \%) } & Lymph node & $4(16.0)$ \\
\hline & Liver & $3(12.0)$ \\
\hline & None & $18(72.0)$ \\
\hline \multirow[t]{7}{*}{ Operative procedure $(\mathrm{n}, \%)$} & Extrahepatic bile duct resection & $18(72.0)$ \\
\hline & Choledochotomy, tumor resection & $2(8.0)$ \\
\hline & Right hepatic trisegmentectomy & $1(4.0)$ \\
\hline & Left hepatectomy & $1(4.0)$ \\
\hline & Liver transplantation & $1(4.0)$ \\
\hline & RFA (for liver metastasis) & $1(4.0)$ \\
\hline & Laparotomy (unresectable) & $2(8.0)$ \\
\hline \multirow[t]{3}{*}{ Origin of histological diagnosis (n, \%) } & Resected specimen & $22(88.0)$ \\
\hline & Biopsy during ERCP & $1(4.0)$ \\
\hline & Biopsy during operation & $1(4.0)$ \\
\hline \multirow[t]{12}{*}{ Immunohistochemistry, positive (n, \%) } & Chromogranin A & $21(84.0)$ \\
\hline & Sph & $12(48.0)$ \\
\hline & NSE & $9(36.0)$ \\
\hline & Gastrin & $4(16.0)$ \\
\hline & Grimelius & $4(16.0)$ \\
\hline & $\mathrm{PP}$ & $4(16.0)$ \\
\hline & Serotonin & $4(16.0)$ \\
\hline & CD56 & $2(8.0)$ \\
\hline & Cytokeratin 7 & $2(8.0)$ \\
\hline & $\mathrm{CDX} 2$ & $1(4.0)$ \\
\hline & Cytokeratin 19 & $1(4.0)$ \\
\hline & VIP & $1(4.0)$ \\
\hline \multicolumn{2}{|l|}{ Disease-specific death } & $1(4.0)$ \\
\hline \multicolumn{2}{|l|}{ Median observation period (months, range) } & $24(4-132)$ \\
\hline
\end{tabular}

CDX2: Caudal-type homeobox 2; ERCP: endoscopic retrograde cholangiopancreatography; NSE: neuron specific enolase; PP: pancreatic polypeptide; RFA: radiofrequency ablation; Sph: synaptophysin; VIP: vasoactive intestinal peptide.

Surgical margins were negative. No lymph node metastasis was identified.

In the evaluation of pathology, the Ki-67 labeling index was $1-2 \%$. Immunohistochemistry was positive for CD56, chromogranin A, synaptophysin, arginase-1 and HepPar-1 (Figure 4B-D). Finally, the pathological diagnosis was NET of the hilar bile duct which is G1 in World Health Organization classification. The tumor did not invade the liver parenchyma. In addition, there were no other NETs in the gastrointestinal tract or pancreas. So, the NET of this case was diagnosed as primary, and not as a hepatic metastasis from another primary site.
The patient is alive without metastasis or recurrence 11 months after the operation.

\section{Discussion and Literature Review}

NET of the bile duct is quite rare $(1-3,6)$. In the present case, there was no NET in the other organs which might have been the primary site of the disease and the tumor was considered a primary neuroendocrine tumor of the hilar bile duct, rather than a liver or lymph node metastasis from the other organs.

To indicate clinical features and establish a treatment strategy, we reviewed the English literature, in which 25 

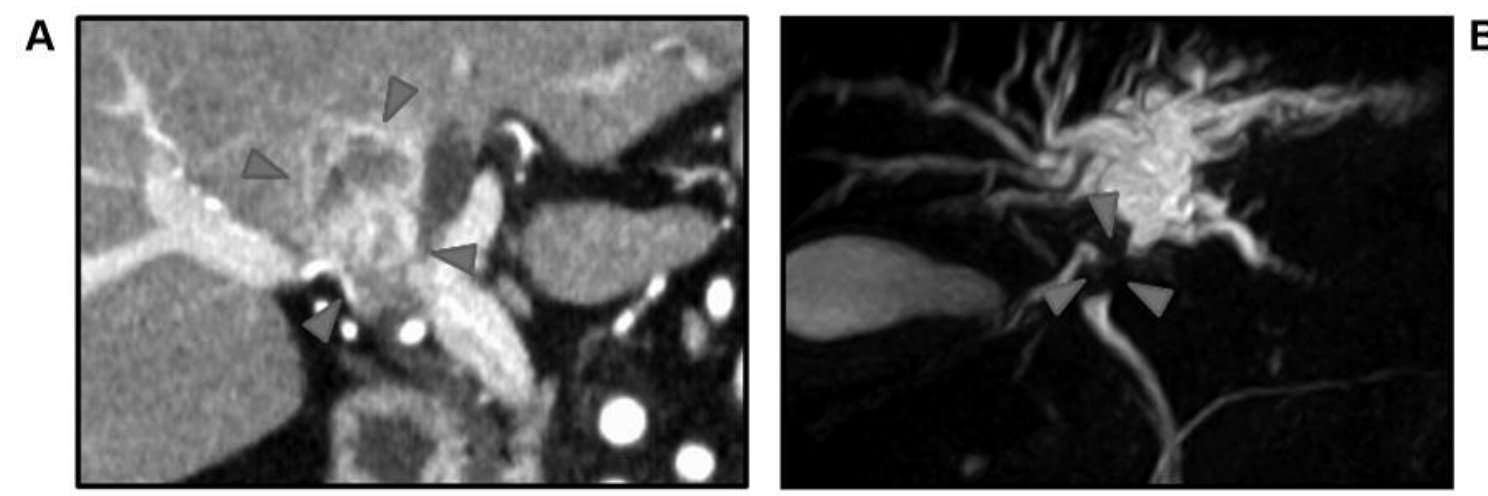

Figure 1. Preoperative image evaluation. Abdominal enhanced CT showed a $27 \mathrm{~mm}$ tumor (arrowheads) at the hepatic portal region (A). Magnetic resonance cholangiopancreatography showed a defect in the bile duct and dilatation of the intrahepatic bile duct $(B)$.
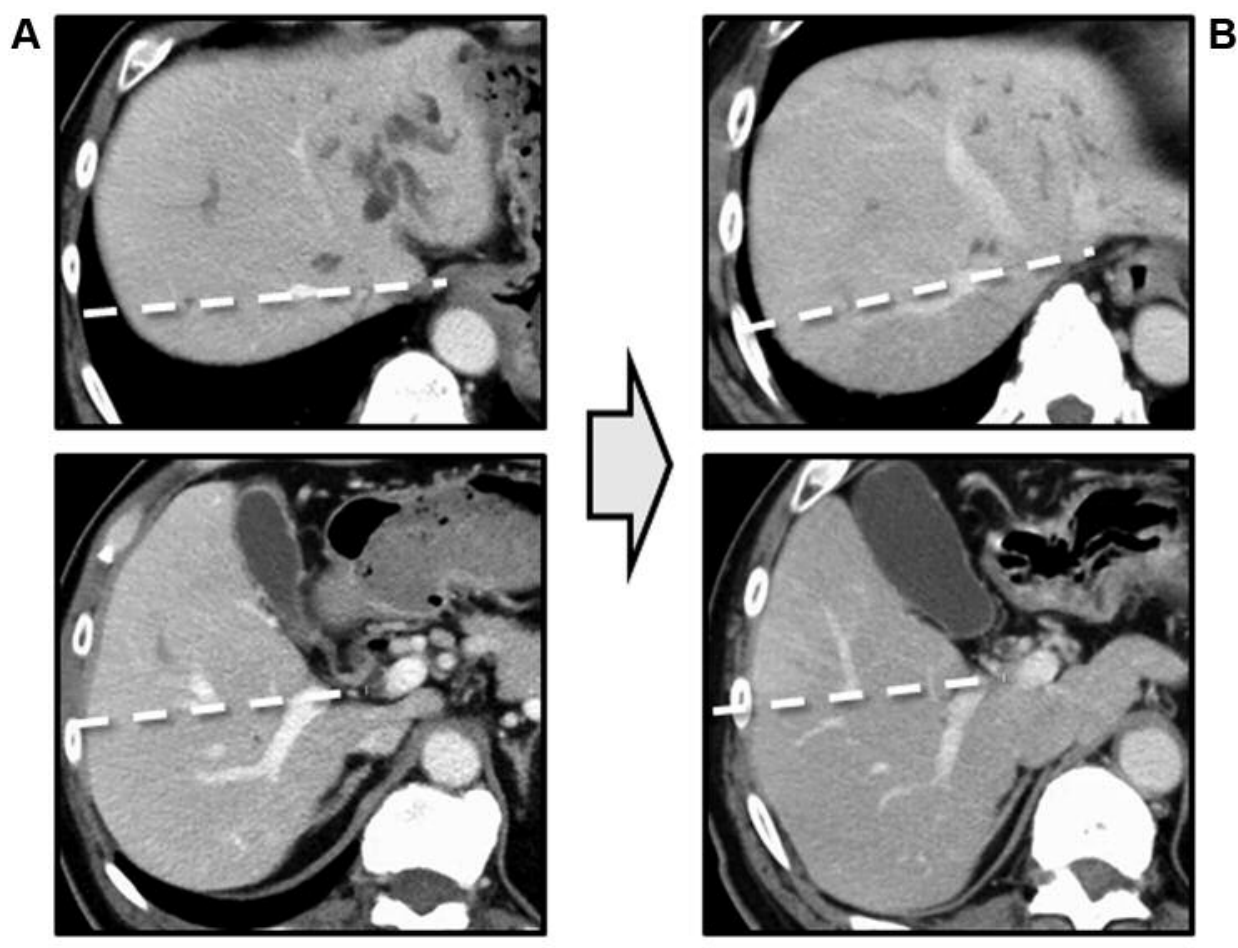

Figure 2. The changes in the volume of the right hepatic lobe after portal vein embolization. Before portal vein embolization (A). After portal vein embolization $(B)$.

cases excluding our case were reported regarding a NET generated from the common hepatic duct (7-28) (Table I). The median age was 37 years (range $=6-71$ years), and 8 (32\%) cases were male and $17(68 \%)$ were female. The most common symptom was jaundice (15 cases, $60 \%)$. Median tumor size was $27 \mathrm{~mm}$ (range=6-55 $\mathrm{mm}$ ). The tumor was located at the common hepatic duct in $13(52 \%)$, followed by common hepatic duct bifurcation in $8(32 \%)$. There was no metastasis in 18 cases $(72 \%)$, whereas lymph node metastasis was observed in 4 cases $(16 \%)(13,14,19,27)$ and liver metastasis in 3 cases $(12 \%)(11,23,25)$.

The most common operative procedure was extrahepatic bile duct resection in $18(72 \%)$ patients, followed by choledochotomy and tumor resection in $2(8 \%)$ patients. For the patients with tumor of the hilar bile duct, hepatectomy was performed in $2(8 \%)$ cases $(12,26)$. A patient with 


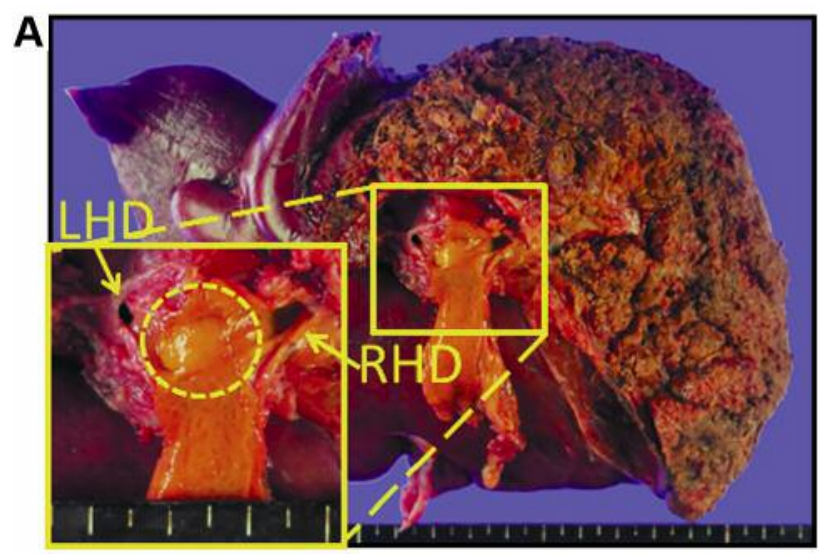

B

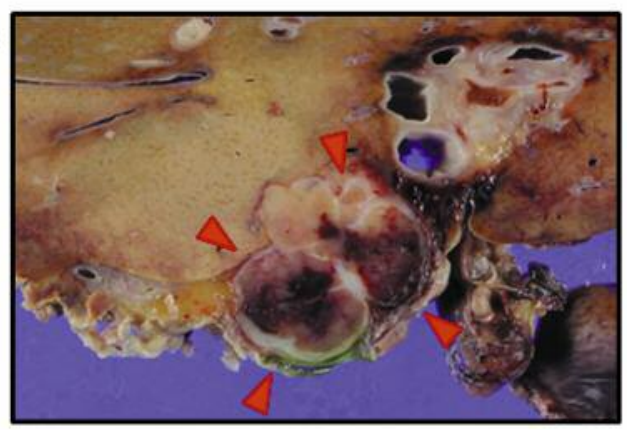

Figure 3. The resected hepatic specimen. The resected tumor appeared as a submucosal tan nodule at the common hepatic duct bifurcation and extending into the left hepatic duct (A). The tumor appeared as a submucosal tan nodule measuring $2.5 \times 2.0 \mathrm{~cm}(B)$.

unresectable tumor received liver transplantation (18). Radiofrequency ablation for liver metastasis was performed in one (4\%) case (23).

Origin of histological diagnosis was derived from the resected specimen in $22(88 \%)$ patients, from a biopsy during ERCP in one (4\%) (25) and from a biopsy during cholecystectomy in another (4\%) patient (26). Immunohistochemical analysis showed that chromogranin A was expressed in $21(84 \%)$ patients, synaptophysin in $12(48 \%)$ patients and neuron specific enolase in $9(36 \%)$ patients.

In a median observation period of 24 months (range $=4$ 132 months), only one (4\%) disease-specific death was reported (11).

In summary, preoperative diagnosis of NET generated from common hepatic duct is difficult. However, appropriate operation such as extrahepatic bile duct resection, and, if needed, combined hepatectomy contribute to better prognosis. Because of the efficacy of molecular targeted therapies such as everolimus and sunitinib for advanced gastroenteropancreatic NETs has been recently reported $(29,30)$, multimodality therapy for patients with metastasized NET of common hepatic duct should be considered in the future.
A

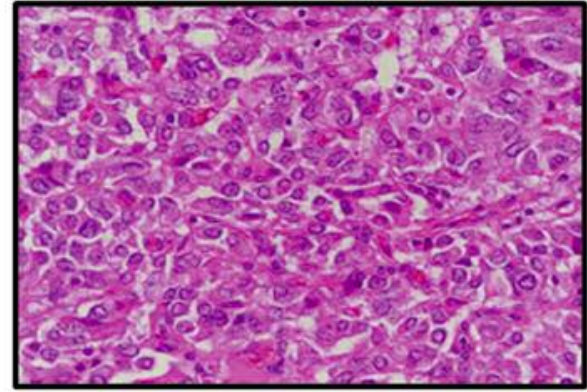

B

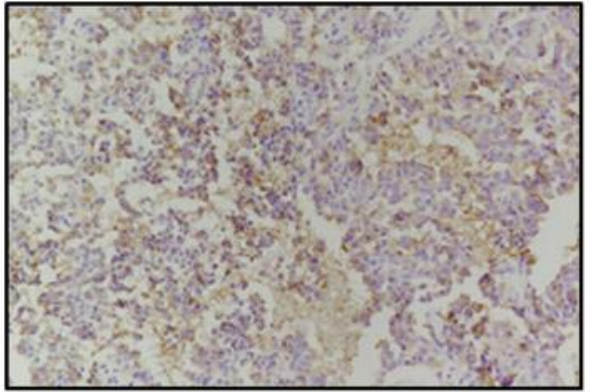

C

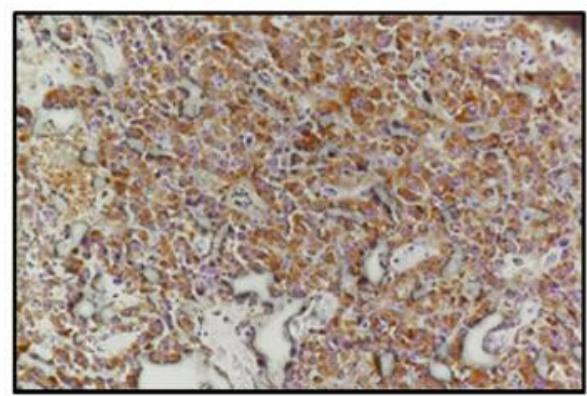

D

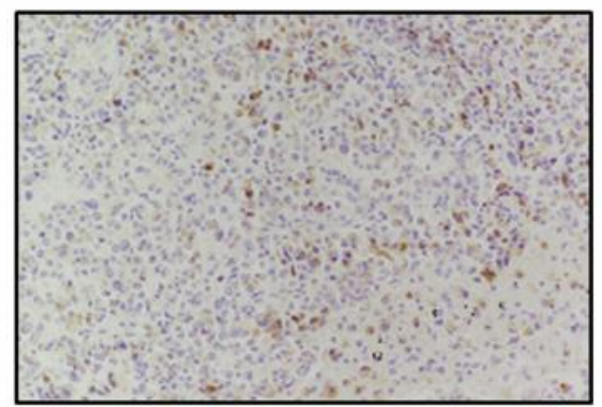

Figure 4. Pathological diagnosis. Hematoxylin and eosin staining of tissue and cell sections. The tumor was composed of sheets of uniform cells with granular cytoplasm, central, round nuclei, and coarse, clustered chromatin (A). Tissue and cell sections were immunohistochemically stained against CD56 (B), Synaptophysin (C), Chromogranin A (D).

\section{Conflicts of Interest}

Naoki Umezaki and the other co-Authors have no conflict of interest to declare regarding this study. 


\section{References}

1 Chamberlain $\mathrm{R}$ and Blumgart L: Carcinoid tumors of the extrahepatic bile duct. A rare cause of malignant biliary obstruction. Cancer 86: 1959-1965, 1999.

2 Raspanti C, Falco N, Silvestri V, Rotolo G, Bonventre S and Gulotta G: Neuroendocrine tumor of the common bile duct: case report. G Chir 37: 275-280, 2016.

3 Felekouras E, Petrou A, Bramis K, Prassas E, Papaconstantinou I, Dimitriou N, Pazaiti A, Tsigris C and Giannopoulos A: Malignant carcinoid tumor of the cystic duct: a rare cause of bile duct obstruction. Hepatobiliary Pancreat Dis Int 8: 640-646, 2009.

4 Yao J, Hassan M, Phan A, Dagohoy C, Leary C, Mares J, Abdalla E, Fleming J, Vauthey J, Rashid A and Evans DB: One hundred years after "carcinoid": epidemiology of and prognostic factors for neuroendocrine tumors in 35,825 cases in the United States. J Clin Oncol 26: 306-372, 2008.

5 Zwan J, Trama A, Otter R, Larranaga N, Tavilla A, Gragera R, Tos A, Baudin E, Poston G and Links T; RARECARE WG: Rare neuroendocrine tumours: results of the surveillance of rare cancers in Europe project. Eur J Cancer 49: 256-578, 2013.

6 Michalopoulos N, Papavramidis T, Karayannopoulou G, Pliakos I, Papavramidis S and Kanellos I: Neuroendocrine tumors of extrahepatic biliary tract. Pathol Oncol Res 20: 765-775, 2014.

7 Jutte D, Bell R, Penn I, Powers J and Kolinjivadi J: Carcinoid tumor of the biliary system. Case report and literature review. Dig Dis Sci 32: 763-769, 1986.

8 Fujita N, Mochizuki F, Lee S, Satoh K, Kobayashi G, Yano A and Shimoda T: Carcinoid tumour of the bile duct: case report. Gastrointest Radiol 14: 151-154, 1989.

9 van der Wal AC1, Van Leeuwen DJ and Walford N: Small cell neuroendocrine (oat cell) tumour of the common bile duct. Histopathology 16: 398-400, 1990.

10 Brown WM 3rd, Henderson JM and Kennedy JC: Carcinoid tumour of the bile duct. A case report and literature review. Am Surg 56: 343-346, 1990.

11 Rodriguez L, Manivel J, Sanchez N and Jessurun J: Carcinoid tumor of the common bile duct: evidence for its origin in metaplastic endocrine cells. Am J Gastroenterol 86: 1073-1076, 1991.

12 Gembala R, Friedman A, Friedman A, Radecki P, Ball D, Hartman G, Rabin L and Caroline DF: Carcinoid of the intrahepatic ducts. Abdom Imaging 18: 242-244, 1993.

13 Bembenek A, Lotterer E, Machens A, Cario H, Krause U and Holzhausen H: Neuroendocrine tumor of the common hepatic duct: a rare case of extrahepatic jaundice in adolescence. Surgery 123: 712, 1998.

14 Perakath B, Chandran B, Srivastava V, Nair A and Sitaram V: Carcinoid tumor of common hepatic duct. Indian J Gastroenterol 18: 127, 1999.

15 Chamberlain $\mathrm{R}$ and Blumgart L: Carcinoid tumors of the extrahepatic bile duct. A rare cause malignant biliary obstruction. Cancer 86: 1956-1965, 1998.

16 Chan C, Franco H, Bell W, Lazenby A and Vickers S: Carcinoid tumor of the hepatic duct presenting as a Klatskin tumor in an adolescent and review of world literature. Hepatogastroenterology 47: 519-521, 2000.

17 Maitra A, Krueger J, Tascilar M, Offerhaus G, Angeles A, Klimstra D, Hruban RH and Albores-Saavedra J: Carcinoid tumors of the extrahepatic bile ducts: a study of seven cases. Am J SurgPathol 24: 1501-1510, 2000.

18 Turrion V, Salas C, Alvira L, Jimenez M, Lucena J and Ardaiz J: Carcinoid tumour of the common bile duct: an exceptional indication for liver transplantation. Transplant Proc 34: 264, 2002.

19 MenezesA, Diver A, Cance D and Diamond T: Carcinoid tumour of the extrahepatic bile duct-report of a case and literature review. Ulster Med J 73: 59-62, 2004.

20 Ligato S, Furmaga W, Cartun R, Hull D and Tsongalis G: Primary carcinoid tumor of the common hepatic duct: a rare case with immunohistochemical and molecular findings. Oncol Rep 13: 543-546, 2005.

21 Hubert C, Sempoux C, Berquin A, Deprez F, Jamar F and Giqot J: Bile duct carcinoids tumors: an uncommon disease but with a good prognosis? Hepatogastroenterology 52: 1042-1047, 2005.

22 Gusani N, Marsh J, Nalesnik M, Tublin M and Gamblin T: Carcinoid of the extra-hepatic bile duct: a case report with longterm follow up and review of literature. The Am Surgeon 74: 8791, 2008.

23 Price T, Thompson G, Lewis J, Lioyd R and Young W: Zollinger-Ellisonsyndrome due toprimary gastrinoma of theextrahepatic biliary tree: three case reports and review of the literature. Endocr Pract 15: 737-739, 2009.

24 Tonnhofer U, Balassy C, Reck C, Koller A and Horcher E: Neuroendocrine tumor of the common hepatic duct, mimicking a choledochal cyst in a 6-year-old child. J Pediart Surg 44: 22$25,2009$.

25 Malecki E, Acosta R, Twaddell W, Heller T, Manning M and Darwin P: Endoscopic diagnosis of a biliary neuroendocrine tumor. Gastrointest Endoscopy 70: 1275-1276, 2009.

26 Squillaci S, Marchione R, Piccolomini M, Colombo F, Bucci F, Bruno $\mathrm{M}$ and Bisceglia $\mathrm{M}$ : Well-differentiated neuroendocrine carcinoma (malignant carcinoid) of the extrahepatic biliary tract: report of two cases and literature review. APMIS 118: 543-556, 2010.

27 Bhalla P, Powle V, Shah R and Jagannath P: Neuroendocrine tumor of common hepatic duct. Indian J Gastroenterol 31: 144146, 2012.

28 Raspanti C, Falco N, Silvestri V, Rotolo G, Bonventre S and Gulotta G: Neuroendocrine tumor of the common bile duct: case report. G Chir 37: 275-280, 2016.

29 Yao J, Pavel M, Bohas C, Cutsem E, Voi M, Brandt U, He W, Chen D, Capdevila J, de Vries EGE, Tomassetti P, Hobday T, Pommier R and Öberg K: Everolimus for the treatment of advanced pancreatic neuroendocrine tumors: overall survival and circulating biomarkers from the randomized, phase III RADIANT-3 study. J Clin Oncol 34: 3906-3913, 2016.

30 Raymond E, Dahan L, Raoul J, Bang Y, Borbath I, LombardBohas C, Valle J, Metrakos P, Smith D, Vinik A, Chen JS, Hörsch D, Hammel P, Wiedenmann B, Van Cutsem E, Patyna S, Lu DR, Blanckmeister C, Chao R and Ruszniewski P: Sunitinib malate for the treatment of pancreatic neuroendocrine tumors. $\mathrm{N}$ Engl J Med 364: 501-513, 2011.

Received December 6, 2018

Revised December 11, 2018

Accepted December 17, 2018 